\title{
Atividades de investigação e a transferência de significados sobre o tema educação alimentar no ensino fundamental
}

\section{Scientific inquiry and transfers of meaning on food education in elementary school}

\author{
Andreia de Freitas Zompero ${ }^{1}$. Helenara Regina Sampaio Figueiredo ${ }^{1}$. \\ Tiago Henrique Garbim $^{1}$
}

\begin{abstract}
Resumo: O objetivo deste estudo acerca da aprendizagem conceitual no ensino de Ciências foi analisar a transferência de significados das atividades de investigação envolvendo a Educação Alimentar. Inicialmente utilizamos atividades para levantamento dos conhecimentos prévios dos estudantes e posteriormente aplicamos uma sequência didática com cinco atividades investigativas referentes à alimentação aos alunos do nono ano do Ensino Fundamental. As atividades investigativas foram elaboradas com base na abordagem do National Research Council e desenvolvidas uma vez por semana. Após esse período aplicamos quatro atividades com situações-problema desafiadoras para averiguarmos se houve a transferência dos conhecimentos das atividades investigativas para novas situações. Comparando os dados obtidos no levantamento dos conhecimentos prévios com os resultados da transferência, foi possível perceber que os estudantes apresentaram desempenho satisfatório quanto à diferenciação entre os conceitos de alimentos e nutrientes e vitaminas e minerais, além da compreensão das funções de alguns minerais para o organismo.
\end{abstract}

Palavras-chave: Educação alimentar. Ensino fundamental. Transferência de significados. Atividade investigativa. National Research Council.

\begin{abstract}
The aim of this study on conceptual learning in science teaching is to analyze scientific inquiry based on the subject Food Education and its transfers of meaning. Initially, survey activities were conducted in order to recognize prior knowledge of students and later, ninth grade students of Elementary School had contact with a didactic sequence of five investigative activities related to the subject. Inquiry was based on National Research Council references and conducted weekly. After that, four challenging activities containing problem situations were applied in order to investigate if transfers of meaning from inquiry to the new situations occured. Comparing the data obtained, it was possible to see that students had a satisfactory performance when they had to distinguish concepts related to food, nutrients, vitamins and minerals. These were better understood than some minerals and their functions in the body.
\end{abstract}

Keywords: Food education. Elementary school. Transfers of meaning. Inquiry. National Research Council.

\footnotetext{
${ }^{1}$ Universidade Norte do Paraná (UNOPAR), Londrina, PR, Brasil. E-mail: <andzomp@yahoo.com.br>.
} 


\section{Introdução}

Os problemas relacionados com a nutrição de crianças e adolescentes têm sido apontados em diversos estudos na atualidade, como os trabalhos de Oliveira e Fisberg (2003) e Carmo et al. (2006). De acordo com Fernandes et al. (2009), o perfil nutricional brasileiro é ambivalente, pois existem ainda no país duas situações distintas. Por um lado, regiões onde há carências nutricionais, apesar de os registros apontarem para um declínio e outras com o aumento da obesidade e das doenças fortemente relacionadas com mudanças no estilo de vida e nos hábitos alimentares, como o excesso de consumo de alimentos ricos em gorduras e açúcares (BATISTA FILHO; RISSIN, 2003).

As políticas públicas no Brasil direcionadas à educação alimentar e nutricional têm procurado atender a população no sentido de promover a educação em saúde. Diversos documentos de ensino foram publicados no país com a finalidade de orientar as propostas curriculares de maneira a contemplar e organizar ações educativas em saúde alimentar e nutricional, conforme estudos de Zompero et al. (2015). Dentre esses documentos destacam-se os Parâmetros Curriculares Nacionais Tema transversal Saúde (BRASIL, 1997) e outro intitulado Política Nacional de Promoção da Saúde publicado em 2010 e 2014. Este último aponta ser um desafio incorporar o tema da alimentação e nutrição no contexto escolar, reconhecendo a escola como um espaço propício à formação de hábitos saudáveis e à construção da cidadania.

As práticas para a promoção da saúde devem ser iniciadas com alunos nos primeiros anos de escolaridade. Esse aspecto é enfatizado por um documento nacional intitulado Referencial Curricular para Educação Infantil que orienta os trabalhos a serem desenvolvidos no Brasil com crianças de zero a cinco anos (BRASIL, 1998).

A construção do conhecimento na escola e o seu uso adequado por parte dos alunos depende do conteúdo, do contexto em que foi empregado, dos processos usados na sua construção e dos propósitos de quem usa (OLIVEIRA; LUZ, 2008). Além disso, os encaminhamentos metodológicos utilizados para ministrar os conteúdos também podem contribuir para a aprendizagem dos alunos. Nesse sentido, é consenso entre os pesquisadores em Didática das Ciências de que aulas que visam a mera transmissão de conteúdos não favorecem a aprendizagem. Admitimos que no Brasil predominam nas aulas de Ciências práticas docentes direcionadas ao ensino transmissivo e conteudista, descontextualizado e memorístico (TEIXEIRA, 2003). Ainda a fragmentação e a linearidade continuam marcando o ensino de Ciências numa perspectiva tradicional nas escolas e a formação dos professores nessa área (MALDANER; ZANON, 2004; MARANDINO, 2003). Essa perspectiva é enfatizada no "Pacto Nacional para o Fortalecimento do Ensino Médio" (BRASIL, 2014, p. 9), ao discutir a necessidade de uma abordagem interdisciplinar para ensino das disciplinas que envolvem as Ciências da Natureza. O caráter enciclopédico e conteudista do ensino também é debatido por autores como Amaral, Xavier e Maciel (2009); Leite e Feitosa (2011). Essa visão favorece que aluno desenvolva uma imagem deformada da Ciência (GIL-PÉREZ et al., 2001).

As pesquisas que envolvem o ensino e aprendizagem de Ciências têm ressaltado a necessidade da apropriação do conhecimento científico pelo aluno, mas também a capacidade de contextualizá-los e transferi-los para novas situações (ZOMPERO; GONÇALVES; SAMPAIO, 2014). Portanto, é necessário o investimento em pesquisas sobre a utilização de metodologias de ensino que atendam a essas necessidades. Estudos como os de Sasseron e Carvalho (2011), 
Suart e Marcondes (2009), Zompero e Laburú (2014), apresentam trabalhos desenvolvidos em sala de aula com a utilização do ensino por investigação e apontam o bom aproveitamento na aprendizagem dos estudantes quando submetidos às práticas investigativas. Neste modelo de ensino que tem como base a teoria de John Dewey no final da década de 30 e Schwab (1962), as atividades de aprendizagem são desenvolvidas a partir de um problema (DEBOER, 2006; WONG; PUGH, 2001).

Esta metodologia de ensino, a qual sofreu algumas modificações propostas por diversos autores, apresenta-se relevante do ponto de vista pedagógico, por contribuir com a aprendizagem de procedimentos e habilidades, além de conceitos (AZEVEDO, 2004; CAMPOS; NIGRO, 1999). No entanto, apesar de muitas publicações direcionadas ao ensino de Ciências, poucas modificações têm efetivamente ocorrido nas salas de aula da escola pública no Brasil. Neste sentido Marandino (2003), argumenta haver ampliação do número das pesquisas do campo educacional. A autora ressalta que os resultados desses estudos encontram resistências à sua aplicação na prática pedagógica, possivelmente, por motivo que a prática dos docentes é marcada por perspectivas tradicionais de ensino e aprendizagem, seja por motivos políticos e econômicos da própria educação ou por problemas na própria formação do professor de Ciências.

Conforme mencionado anteriormente, um aspecto que merece relevância é a necessidade de que os estudantes realizem a transferência dos conhecimentos escolares para situações de sua vivência cotidiana. Pozo (1998) argumenta que a transferência ou generalização dos conhecimentos adquiridos para um novo contexto é um dos problemas de aprendizagem mais difíceis de superar.

Em recente estudo de revisão bibliográfica de pesquisas sobre a transferência de conhecimentos para novas situações, Salmerón (2013) argumenta que os trabalhos empíricos sobre transferência, bem como as atividades de ensino que favoreçam a sua avaliação, são muito pobres no meio educacional. Por isso, o autor afirma que os estudos sobre transferência num futuro próximo passarão a ser um tópico central na área de Didática. Ben-Hur (2013) aponta que a realização da transferência depende da qualidade da experiência de aprendizagem. Para Ausubel (2000), a transferência é uma das condições para saber se o aluno realizou aprendizagem significativa. Assim, a transferência dos conhecimentos apropriados na escola para outras situações é um dos principais objetivos nas situações de ensino e aprendizagem. Há, portanto, necessidade de estudos para averiguar a transferência que os estudantes conseguem realizar quando submetidos a diferentes metodologias de ensino.

Neste estudo elaboramos uma sequência didática com cinco atividades investigativas referentes ao tema alimentação e aplicamos a alunos do nono ano do Ensino Fundamental. Temos por objetivo analisar a transferência de significados das atividades de investigação, estas que compõem uma sequência didática, para situações-problema relativas ao mesmo conteúdo apresentado na perspectiva da teoria de Ausubel (2000).

\section{Marco teórico}

Os hábitos alimentares são desenvolvidos na infância, fase em que as crianças estão mais receptivas a receberem informações, incorporar novos hábitos e difundir novas informações, principalmente adquiridas no ambiente escolar. Desse modo a escola se constitui um 
espaço propício para fomentar os hábitos alimentares das crianças, visto que é nesse ambiente que diversos indivíduos atuam de modo a corroborar com o processo educativo e de maneira inconsciente influencia nas escolhas e no comportamento do indivíduo.

A escola é um espaço importante para o desenvolvimento de um programa de educação para a saúde. Distingue-se das demais instituições por oferecer a possibilidade de educar por meio da construção de conhecimentos resultantes dos saberes científicos veiculados pelas diferentes disciplinas e aqueles trazidos pelos alunos e seus familiares e que expressam crenças e valores culturais peculiares (BRASIL, 2009; SOBRAL; SANTOS, 2010).

No Brasil, a portaria $n^{\circ} 687$ de 2006, redefinida em 2014, regulamenta a Política Nacional de Promoção da Saúde (BRASIL, 2006). O documento apresenta algumas diretrizes para o trabalho com o tema alimentação. Dentre as que são relativas à participação da escola estão: desenvolver ações para a promoção da alimentação saudável no ambiente escolar; divulgação de iniciativas que favoreçam o acesso à alimentação saudável nas escolas públicas e privadas; implementação de ações de promoção da alimentação saudável no ambiente escolar; produção e distribuição do material sobre alimentação saudável para inserção de forma transversal no conteúdo programático das escolas em parceria com as secretarias estaduais e municipais de saúde e educação; produção e distribuição de vídeos e materiais instrucionais sobre a promoção da alimentação saudável nas escolas.

Além dessa portaria há diversos outros documentos de ensino que reafirmam a necessidade do trabalho com o tema referente à educação alimentar e nutricional. Em 2009 foi promulgada a Lei no 11947 (BRASIL, 2009). Em seu parágrafo segundo aponta que a inclusão da educação alimentar e nutricional no processo de ensino e aprendizagem deve perpassar o currículo escolar, abordando o tema alimentação, nutrição e o desenvolvimento de práticas saudáveis de vida, na perspectiva da segurança alimentar e nutricional. Os documentos apontam direcionamentos para o trabalho com as crianças já na Educação Infantil, passando pelos Anos Iniciais e Finais do Ensino Fundamental até o Ensino Médio. As práticas sugeridas indicam para um trabalho que possibilite ao aluno uma participação ativa frente aos problemas referentes à saúde.

As atividades investigativas que compõem a metodologia de ensino por investigação promovem a participação intelectual ativa do aluno em sua aprendizagem. Os estudos de Sasseron e Carvalho $(2011,2014)$ com alunos da Educação Básica mostram o desenvolvimento da capacidade argumentativa e o papel das evidências e dos dados no estabelecimento de justificativas em atividades de investigação. Os trabalhos de Suart e Marcondes (2009) apontam o desenvolvimento de habilidades cognitivas em alunos que participaram de atividades experimentais investigativas na disciplina de Química.

O ensino por investigação que tem por base a aplicação de atividades investigativas, deve partir sempre de um problema que poderá ser tanto apresentado ao aluno pelo professor ou partir dos próprios alunos. A literatura aponta que o termo "ensino por investigação" apresenta diferentes abordagens, conforme os estudos de Zompero e Laburú (2011). Por esse motivo o documento americano do National Research Council (2000), apresentou algumas das características que devem estar presentes em uma atividade para ser considerada investigativa. São elas: engajamento dos estudantes na atividade, priorização de evidências, formulação de explicações para as evidências, articulação das explicações ao conhecimento científico, comunicação e justificação das explicações. As características aqui mencionadas são compatíveis 
com as apresentadas por alguns autores como, por exemplo, Newman et al. (2004), quanto à necessidade do engajamento nas atividades, Watson, Swain e Mc Robbie (2004) e Newman et al. (2004), relativo à priorização de evidências, Gil-Pérez e Valdés Castro (1996) quanto à formulação de explicações sobre o fenômeno em estudo, articulação das explicações dos alunos ao conhecimento científico e comunicação dessas explicações, Del Carmen (1988); Zabala (1992); Gil-Perez (1993); Rodríguez e León (1995), quanto à comunicação dos resultados.

A emissão de hipóteses também é outro aspecto relevante que deve ser contemplado no ensino por investigação. Essa necessidade é enfatizada por autores como Carvalho (2006), Azevedo (2004), Rodríguez e León (1995). Para elaborar as atividades que compõem a sequência didática de nosso estudo tomamos por base as características do National Research Council (2000).

A transferência de conhecimentos apropriados nas situações de ensino na escola para situações cotidianas tem sido estudada por diversos autores. A transferência é a capacidade de aplicar conhecimento ou procedimentos aprendido em um contexto para novos contextos. Ausubel, Novak, J. e Hanesian (1976) enfatiza que a transferência de significados é dita positiva quando o aprendiz elabora nas atividades de ensino significados claros, estáveis e organizados. De acordo com Sánchez e López Fernández (2011), a transferência positiva ocorre quando a experiência e o conhecimento prévio facilitam, apoiam e reforçam o processo de resolução de novos problemas ou aprendizagens.

Mas a produção de significados depende também das ideias âncoras, os subsunçores, já existentes na estrutura cognitiva do aluno. A falta de clareza dos modos de relação entre as ideias novas e os conceitos já existentes na estrutura de conhecimento pode produzir o que Ausubel (1976) denomina como transferência negativa, pelo fato de o aluno não transferir satisfatoriamente os novos significados para situações similares, atribuindo significado impróprio àquilo que aprende.

Para Ausubel (2000) é possível que toda a aprendizagem significativa também envolva, necessariamente, a transferência. A experiência de aprendizagem resulta numa nova transferência, por meio da alteração da estrutura cognitiva. Moreira (2005) resume a aprendizagem significativa como aprendizagem com significado, compreensão, sentido, capacidade de transferência; oposta à aprendizagem mecânica.

De acordo com Perrenoud et al. (2002), a transferência de conhecimentos deve ser desenvolvida em situações didáticas apropriadas e que esse procedimento não tem sido trabalhado de maneira suficiente nas escolas. Neste sentido é relevante diferenciarmos retenção e transferência de conhecimentos.

Conforme apontado por Almeida, Coutinho e Chaves (2009), os testes de retenção avaliam a habilidade para reproduzir ou reconhecer o material apresentado. Os mais comuns consistem em lembrar, processo no qual é pedido aos alunos que reproduzam o que foi apresentado. Por exemplo, escrever tudo que eles puderem lembrar de uma lição que leram e reconhecimento no qual é pedido aos aprendizes para selecionar o que foi dado, por exemplo, como em uma questão de múltipla escolha ou avaliar se um item apresentado em uma questão é verdadeiro ou falso.

Os autores afirmam que os testes de transferência diferenciam-se dos testes de retenção por avaliarem a compreensão do estudante, isto é, a habilidade para construir uma representação mental coerente do material apresentado. Portanto, para avaliar se houve transferência os aprendizes devem ser capazes de resolver problemas aplicando seus conhecimentos em novas 
situações, considerando o ensino de Ciências. Para isso, o professor deve elaborar situações de ensino e aprendizagem não familiares ao aluno, porém, envolvendo o mesmo conteúdo de ensino (com atributos essenciais que deveriam já ser conhecidos), testando-se a substantividade da aprendizagem.

Os estudos de Zoller (2013) referentes a Higher-Order Cognitive Skills (HOCS) e Lower-Order Cognitive Skills (LOCS) também ressaltam a necessidade de o aluno realizar a transferência dos conhecimentos aprendidos na escola para novas situações e para isso o ensino deve propor situações que possam desafiá-los.

De acordo com Salmerón (2013), faz-se necessário usar diferentes atividades de instrução, métodos mais inovadores, para permitir aos alunos aplicarem o que aprenderam na sala de aula a outros contextos, bem como investir em pesquisas nessa área para elucidar os mecanismos de transferência e as situações de ensino que a favorecem. O mesmo autor salienta que alguns tipos de atividade de ensino podem facilitar a transferência como aquelas que envolvem análises e comparação de determinados casos, os trabalhos em grupo, utilizar tarefas que promovam o engajamento do estudante e aumentem sua motivação em resolvê-las.

Segundo Sánchez e López Fernández (2011), autores como Frederiksen (1984), Egan e Greeno (1973), entre outros, indicam que um requisito para a transferência é ter adquirido conhecimentos consolidados; isto somente ocorre nos processos de aprendizagem que promovam as interconexões e relações entre conceitos.

Para Ausubel (2000), na formação conceitual, os atributos específicos do conceito adquirem-se por meio de experiências diretas e de fases sucessivas de formulação de hipóteses, testes e generalização.

Para a transferência é necessário, segundo Tapia, Terrero e Cabral (2015), que estudantes sejam capazes de abstrair as características básicas do objeto de aprendizagem, a memorização mecânica não é suficiente neste processo, é necessário compreensão e aprendizagem significativa.

\section{Procedimentos Metodológicos}

Para realizar o estudo elaboramos uma sequência didática, conforme Zabala (1998), com cinco atividades investigativas referentes ao tema alimentação e aplicamos a 13 alunos do nono ano do Ensino Fundamental numa escola pública de Londrina, que já haviam tido acesso a esse conteúdo no ano anterior de escolaridade. Neste estudo apresentaremos apenas as três atividades referentes à identificação de nutrientes, obesidade e doenças relativas às carências nutricionais por terem contemplado as atividades que os alunos responderam inicialmente para identificarmos seus conhecimentos prévios. Trata-se de uma pesquisa com abordagem qualitativa do tipo descritiva e interpretativa, levando em consideração procedimentos quantitativos no tratamento dos dados, por meio da apresentação de tabelas de frequências relativas, as quais contribuíram para as análises.

As atividades investigativas propostas na sequência didática foram preparadas com base nas características do National Research Council (2000) e aplicadas por duas professoras pesquisadoras autoras deste estudo. Inicialmente foi realizada uma avaliação para levantar os conhecimentos prévios dos alunos referentes aos conteúdos considerados básicos sobre nutrição como, por exemplo, diferenças entre os tipos de nutrientes dos alimentos, identificação de vitaminas e 
minerais e também algumas doenças mais comuns apresentadas em livros didáticos referentes à carência de nutrientes como o ferro e o cálcio ou seu excesso na alimentação como o sódio. Para esse levantamento, a pirâmide alimentar, tabelas e rótulos de alimentos foram utilizados.

$\mathrm{Na}$ semana seguinte iniciou-se a aplicação da sequência didática. Realizou-se uma atividade por semana durante aproximadamente dois meses. Os alunos foram organizados em grupos com uma média de 4 participantes cada. Todas as atividades partiam de um problema, ou de um estudo de caso a ser investigado. Uma das atividades foi do tipo experimentação. Em seguida à apresentação do problema, os alunos teriam que discuti-lo e posteriormente emitir suas hipóteses para a resolução. Os alunos teriam que indicar as possíveis pistas que os levaram a emitir as hipóteses. Momento em que foi possível a eles perceberem as evidências. Após as discussões e anotações das hipóteses, os estudantes eram então levados ao laboratório de informática da escola para pesquisarem textos que pudessem levá-los a resolver o problema.

As atividades eram sempre finalizadas com uma conclusão cujos estudantes deveriam escrever como forma de comunicarem os resultados obtidos com a leitura de materiais bibliográficos, consultados na internet com a orientação das pesquisadoras, e no confronto com as hipóteses anotadas para possíveis respostas aos problemas apresentados no início de cada atividade.

Neste estudo, apresentaremos somente três das atividades investigativas e os resultados das respectivas atividades de transferência aplicadas devido às limitações de espaço.

\section{Atividade Investigativa 1 - Carências nutricionais}

Analise a situação abaixo e observe as orientações para resolver a questão:

Marcelo é um senhor de 50 anos que não tem bons hábitos alimentares. Ele procurou um médico por não estar se sentindo bem. O médico lhe disse estar com algumas carências nutricionais de sais minerais, devido aos seguintes sintomas que apresenta:

1. Osteoporose e seus ossos são fracos;

2. Muito cansaço e anemias frequentes;

3. Câimbras musculares frequentes.

Após a leitura dos sintomas do senhor Marcelo, discuta com seu grupo e indique suas hipóteses para a carência de minerais que pode estar relacionada com cada um dos sintomas que ele apresenta. Após consultar materiais na internet, escreva um texto para concluir a atividade confrontando suas hipóteses com as informações obtidas nos textos.

\section{Atividade investigativa 2 - Carências nutricionais com análise de tabelas alimentares}

Catharina é uma adolescente de 15 anos. Sua alimentação não é saudável e predominam os produtos industrializados. Não consome com frequência carnes, verduras, frutas e leite. Por isso, começou a apresentar alguns sintomas. Leia abaixo um pouco sobre o histórico da Catharina.

1. Cabelos e principalmente unhas quebram com frequência;

2. Peso acima da média para meninas de sua idade;

3. Em sua família é comum casos de pessoas com diabetes e pressão alta, por isso, ela precisa evitar comer em excesso alguns tipos de alimentos. 
Suponha que você seja um (a) nutricionista. Analise as tabelas nutricionais e indique os alimentos que estariam indicados para cada sintoma apresentado por Catharina. No último caso indique quais alimentos deveriam ser consumidos com menor frequência.

Após consulta de materiais na internet, escreva um texto para concluir a atividade confrontando suas hipóteses com as informações obtidas nos textos.

\section{Atividade investigativa 3 - Alimentação de Gabriel}

Gabriel é um adolescente de dezoito anos. Ele está bem acima do peso para sua idade. Conheça um pouco sobre seu estilo de vida. Ele não gosta de fazer atividade física, por isso, tem uma vida mais sedentária. Em sua família as pessoas não são gordas, sendo assim, ele não tem "tendência" para engordar. Já consultou um endocrinologista que constatou que ele não apresenta problemas hormonais. Agora sua mãe vai levá-lo a uma nutricionista para fazer um controle de sua alimentação. Mas como ele não tem fatores genéticos que interferem no seu peso e também não tem problemas hormonais seu pai é contra o tratamento com nutricionista. Ele acha que só fazer atividade física resolverá seu problema.

Conheça alguns dos alimentos que Gabriel consome todos os dias.

A mudança de hábitos alimentares pode resolver o problema de Gabriel? Por quê? Que pistas levou você a chegar nessa conclusão? Após discussões e consulta ao material elabore um texto com sua conclusão.

Nessa atividade os alunos tiveram acesso a diversos rótulos de alimentos industrializados, como biscoitos, chocolates e sorvetes para caracterizar o tipo de alimentos consumidos por Gabriel.

As atividades para averiguar a transferência foram aplicadas após uma semana da realização da sequência didática e resolvidas individualmente pelos alunos. Apresentaremos abaixo quatro atividades de transferência aplicadas aos estudantes. A primeira foi realizada com base numa versão mais atual da pirâmide alimentar, diferente daquela analisada para averiguar os conhecimentos prévios.

\section{Atividade de transferência 1}

Observe a nova pirâmide alimentar de 2015. Ela é dividida em quatro níveis. A base é o nível 1 e o topo é o nível 4. Indique:

a) Nutriente predominante encontrado na base da pirâmide;

b) Nutrientes que podem ser encontrados no terceiro nível.

\section{Atividade de transferência 2}

Considerando uma dieta de 2000 calorias diárias, os componentes do topo da pirâmide devem ser consumidos somente 1 a 2 porções diárias. Por que deve haver menor consumo desses alimentos diariamente? $\mathrm{O}$ que pode ocorrer com as pessoas se consumirem em excesso?

\section{Atividade de transferência 3}

Ao observar a pirâmide alimentar é possível perceber que as hortaliças e frutas ocupam o segundo nível. Indique duas vitaminas e três minerais que podem ser encontrados em frutas e hortaliças. 


\section{Atividade de transferência 4}

Para resolver essa atividade foi entregue aos estudantes uma bula de medicamento para complementação alimentar. Segue abaixo o texto entregue aos alunos.

Para tratar um paciente com algumas carências nutricionais um médico indicou para o tratamento um medicamento para complemento alimentar com a bula abaixo. $\mathrm{O}$ paciente apresentava os sintomas: anemia, frequentes câimbras musculares, cabelos e unhas que se quebram com frequência e osteoporose.

a) $\mathrm{O}$ medicamento apresenta nutrientes para todos os sintomas? Indique quais os nutrientes o remédio apresenta para tratar os sintomas. Coloque o nutriente e o sintoma correspondente;

b) Há risco do medicamento provocar aumento de peso? Por quê?;

c) Há algum componente na bula que provoque aumento de pressão arterial? Se tiver indique qual poderia ser.

\section{Análise dos dados}

No levantamento dos conhecimentos prévios, conforme já exposto acima, foi pedido aos alunos que identificassem os nutrientes de cada nível da pirâmide alimentar. Dos treze alunos participantes do estudo, $77,78 \%$ indicaram nomes de alimentos e não de nutrientes, o que demonstra que não apresentam clareza sobre os conceitos de nutriente e alimento. $\mathrm{Na}$ pergunta dois, em que foi pedido aos estudantes para analisarem diferentes tabelas alimentares e apontarem minerais e vitaminas encontrados nas tabelas, nenhum dos alunos participantes indicou corretamente os nutrientes solicitados evidenciando que eles não sabiam diferenciar vitaminas de minerais.

Nas respostas à questão 3 , na qual foi pedido aos alunos que observassem rótulos de alimentos e indicassem os que deveriam ser evitados por uma pessoa que deseja emagrecer, nenhum aluno acertou a resposta completa dos alimentos representados. Dos participantes 50\% acertaram pelo menos um dos alimentos das tabelas; $50 \%$ erraram a questão, pois colocaram nomes de outros alimentos e não os da tabela, como, por exemplo, macarrão, bacon, lanches, pastéis que não correspondiam aos alimentos que lhes foram apresentados. Sobre a conclusão, dos alunos que responderam parcialmente, apenas $20 \%$ se referiram aos carboidratos e gorduras.

$\mathrm{Na}$ questão 4 os estudantes deveriam indicar dos rótulos de alimentos analisados, quais deveriam ser evitados por uma pessoa que tenha hipertensão. Obtivemos que 33,33\% dos alunos relacionaram corretamente o alimento à quantidade de sódio, 22,22\% justificaram o açúcar como causa de hipertensão e 22,22\% justificaram ser devido à quantidade de gordura. Os dados indicam que 44,44\% dos alunos não têm clareza das relações entre o mineral sódio e hipertensão.

$\mathrm{Na}$ última pergunta foi pedido aos estudantes que indicassem, com base nos rótulos analisados, o alimento que deveria ser consumido por pessoa com anemia. Dos participantes, $55,55 \%$ concluíram ser o alimento que apresentava o mineral ferro em sua composição, o que demonstra ser esse um nutriente conhecido dos estudantes.

Os dados, apontados acima referentes aos conhecimentos prévios dos alunos, mostram que apesar de os estudantes do nono ano já terem tido acesso ao conteúdo sobre "alimentos", 
não apresentam significados claros e estáveis quanto ao conteúdo. Consideramos preocupante a dificuldade encontrada em diferenciar os minerais e vitaminas dos demais nutrientes quando analisaram tabelas e rótulos alimentares, bem como a falta de clareza apresentada por alguns estudantes entre alimentos e nutrientes. A falta de compreensão desses conceitos básicos dificulta o aproveitamento dos estudantes em trabalhos de conscientização que visam a educação alimentar, pois conforme os PCN (BRASIL, 1997) tema transversal saúde, os conceitos instrumentalizam os alunos para a crítica diante dos desafios que lhes serão apresentados de maneira crescente em suas relações sociais, enfrentamento de situações adversas, possibilitando a transformação de hábitos e reavaliar crenças e tabus.

Estudos de Luz e Da Poian (2005), Piperakis (2007), Oliveira e Luz (2008), Carvalho e Bossolan (2009), Tamayo, Juánez e Macía (2014) também apontam concepções que os estudantes apresentam sobre nutrientes dos alimentos. As controvérsias apresentadas entre esses dois conceitos, como também a diferenciação entre os tipos de nutrientes, são comuns nos resultados dos estudos acima. Considerando que alguns desses estudos foram realizados com alunos de cursos de graduação, admitimos a necessidade de investimentos em práticas pedagógicas que contribuam para a aprendizagem dos alunos quanto aos conceitos relativos ao tema alimentação na Educação Básica. Neste nível de escolaridade os alunos têm oportunidade de aprender conceitos e procedimentos que serão base para aprendizagens futuras.

Após o levantamento dos conhecimentos prévios e realização das atividades investigativas pelos alunos, aplicamos as quatro atividades de transferência após uma semana. As respostas para indicar a transferência foram organizadas em categorias. Para cada pergunta estabelecemos categorias considerando o agrupamento das respostas para as quais foi estabelecido o percentual de acertos.

Nos quadros 1 e 2 organizamos as respostas dos alunos referentes à atividade de transferência número 1. Tivemos por objetivo averiguar se os estudantes conseguiam diferenciar com mais clareza nutrientes de alimentos, a partir da leitura de uma pirâmide alimentar mais atualizada em relação àquela apresentada para levantar os conhecimentos prévios e com nova organização dos alimentos por níveis. As respostas possibilitaram categorias que se referem aos alimentos e as que indicam os nutrientes. Classificamos na categoria "alimentos", as respostas dos alunos que se referem a alimentos como pão, macarrão, frutas, carnes e não aos seus nutrientes, como carboidratos, vitaminas, minerais, proteínas e lipídios. Para indicar quais foram os nutrientes citados pelos alunos nos diferentes níveis da pirâmide, apontamos os encontrados em maior quantidade. Por fim, reunimos na categoria "Outros nutrientes", todos aqueles que os alunos citaram com menor frequência.

Quadro 1. Tabulação dos dados da atividade 1 item a. Nutriente predominante na base da pirâmide

\begin{tabular}{|l|c|}
\hline \multicolumn{1}{|c|}{ Respostas } & Frequências \\
\hline Alimentos & $42,86 \%$ \\
\hline Carboidratos & $28,57 \%$ \\
\hline Outros nutrientes & $28,57 \%$ \\
\hline
\end{tabular}

Fonte: elaborado pelos autores a partir de dados da pesquisa. 
Quadro 2. Tabulação item B. Nutrientes que podem ser encontrados no terceiro nível

\begin{tabular}{|l|c|}
\hline \multicolumn{1}{|c|}{ Respostas } & Frequências \\
\hline Outros Nutrientes & $62,5 \%$ \\
\hline Vitaminas e minerais & $37,5 \%$ \\
\hline Alimentos & $37,5 \%$ \\
\hline
\end{tabular}

Fonte: elaborado pelos autores a partir de dados da pesquisa.

Pelos dados apresentados é possível perceber que muitos estudantes ainda confundem nutrientes com alimentos. Esse fato demonstra que esses estudantes não conseguiram transferir esses conhecimentos para as situações-problema apresentadas na transferência. No entanto, esses dados mostram que a diferenciação entre alimentos e nutrientes ficou mais clara para os estudantes após terem realizado as atividades investigativas devido ao fato de que a análise dos conhecimentos prévios mostrou que $77,78 \%$ dos estudantes não faziam distinção entre esses dois conceitos antes da aplicação das atividades. Na identificação dos nutrientes da base da pirâmide alimentar, os carboidratos foram citados por $28,57 \%$ dos alunos indicando nesse caso haver o que Ausubel (2000) denomina de transferência positiva porque os significados são precisos e estáveis e o mesmo percentual de estudantes, indicados na categoria "outros nutrientes", demonstrou realizar transferência negativa pelo fato de que conseguiram diferenciar nutrientes de alimentos, porém não distinguiram com clareza os nutrientes do terceiro nível que seriam os minerais e vitaminas, correspondendo às frutas e verduras que aparecem nesse nível.

Na pergunta 2 foi pedido aos estudantes que explicassem porque os alimentos que ocupam o topo da pirâmide devem ser consumidos em menor quantidade considerando uma dieta de 2000 calorias. Nosso objetivo nesta questão foi averiguar se os estudantes conseguiram relacionar a presença de lipídios e carboidratos na dieta com o aumento de peso. Obtivemos as categorias do Quadro 3.

Quadro 3. Tabulação dos dados da atividade 2

\begin{tabular}{|l|c|}
\hline \multicolumn{1}{|c|}{ Respostas } & Frequências \\
\hline Podem ficar com diabetes & $50 \%$ \\
\hline Podem ficar com colesterol & $33,33 \%$ \\
\hline Podem ficar obesas pelas calorias que contém & $22,22 \%$ \\
\hline
\end{tabular}

Fonte: elaborado pelos autores a partir de dados da pesquisa.

Na imagem da pirâmide que os estudantes analisaram, aparece no topo, além do desenho, a indicação por escrito de açúcares e doces, óleos e gorduras. Nas respostas é possível perceber que $22,22 \%$ dos estudantes relacionaram corretamente a ingestão de alimentos calóricos com a obesidade. No entanto, a predominância foi para diabetes. Ressaltamos que nas atividades 
investigativas aplicadas não houve ênfase na relação entre diabetes e alimentos calóricos, mas sim destes com a obesidade. Nesse caso, por terem indicado tanto diabetes quanto o aumento de colesterol referentes a uma dieta com 2000 calorias diárias, consideramos que esses estudantes não relacionaram corretamente os alimentos do topo da pirâmide com aumento de peso, mas corretamente a outros fatores. Nesse caso, admitimos ter ocorrido o que Ausubel (2000) denomina de transferência negativa, pelo motivo de que os alunos sabem que pode haver problemas no consumo excessivo desses alimentos, mas não conseguiram relacionar corretamente as necessidades diárias de calorias indicadas no enunciado da questão com os alimentos do topo da pirâmide alimentar. Os dados mostram que somente $22,22 \%$ dos estudantes fizeram transferência positiva apresentando significados coerentes ao conhecimento científico e esperado. No entanto, esse resultado é ligeiramente superior aos $20 \%$ de respostas corretas apresentadas pelos alunos nas atividades para identificação dos conhecimentos prévios quanto aos alimentos calóricos que devem ser evitados por pessoas que desejam emagrecer.

A atividade 3 foi relativa à compreensão e diferenciação estabelecida entre vitaminas e minerais. Com as respostas dos estudantes foi possível estabelecer as seguintes categorias que se encontram no Quadro 4.

Quadro 4. Tabulação dos dados da atividade 3

\begin{tabular}{|l|c|}
\hline \multicolumn{1}{|c|}{ Respostas } & Frequências \\
\hline Indicaram vitaminas e minerais nas respostas & $88 \%$ \\
\hline Frutas e verduras & $11,11 \%$ \\
\hline Citam o ferro e cálcio dentre os minerais & $66,67 \%$ \\
\hline Citam o sódio & $33,33 \%$ \\
\hline Citam o zinco & $11,11 \%$ \\
\hline
\end{tabular}

Fonte: elaborado pelos autores a partir de dados da pesquisa.

Apenas $11,11 \%$ dos alunos não souberam responder a questão, colocando que vitaminas estavam nas frutas e os minerais nas hortaliças. Tivemos $88,88 \%$ que citaram nomes de vitaminas (A, B, C, D) e de minerais. Em relação aos minerais, o ferro e o cálcio foram citados com maior frequência sendo $66,67 \%$, o sódio em $33,33 \%$, o zinco e os carboidratos apareceram em $11,11 \%$ das respostas.

Ao confrontarmos os dados dessa questão com a de número 1, confirma-se que ainda não há clareza por parte de muitos estudantes quanto à distinção entre nutrientes e alimentos. Os dados mostram que os estudantes realizaram transferência negativa, conforme Ausubel (2000), pois conseguem identificar os nutrientes em vitaminas e minerais, mas não têm clareza da diferenciação entre eles, não sabem, portanto, identificar as diferenças.

$\mathrm{Na}$ questão 4, tivemos por objetivos analisar se os alunos conseguiram transferir os significados da atividade investigativa para uma situação-problema em que tiveram que analisar uma bula de medicamento para complementação alimentar associando nutrientes da bula às carências nutricionais apresentadas no caso. A partir das respostas estabeleceu-se as categorias apresentadas no Quadro 5. 
Atividades de investigação e a transferência de significados ...

Quadro 5. Tabulação dos dados da questão 4

\begin{tabular}{|l|c|}
\hline \multicolumn{1}{|c|}{ Respostas } & Frequências \\
\hline Anemia & $50 \%$ \\
\hline Não interfere no peso & $41,66 \%$ \\
\hline Não há risco para hipertensos & $41,66 \%$ \\
\hline
\end{tabular}

Fonte: elaborado pelos autores a partir de dados da pesquisa.

Ao analisarem a bula do medicamento $50 \%$ relacionaram corretamente o mineral ferro ao tratamento da anemia. Na bula não constava presença de carboidratos nem lipídios e também o valor energético. No valor nutricional indicado também não aparecia indicação para o mineral sódio. Em comparação com os dados da pergunta 4 realizada para levantar os conhecimentos prévios dos estudantes, em que o sódio aparece nas respostas como 33,33\%, percebe-se um avanço na compreensão dos alunos quanto ao sódio como mineral responsável pela hipertensão.

Comparando os resultados dos conhecimentos prévios com os das atividades sobre a transferência, é possível perceber que os melhores desempenhos em aprendizagem ocorreram quanto ao reconhecimento das diferenças entre nutrientes e alimentos; identificação das vitaminas e minerais e na indicação do sódio como nutriente causador da hipertensão.

No que se refere à compreensão quanto à deficiência do mineral ferro como causador da anemia, os dados mantiveram-se estáveis. Os menores desempenhos na aprendizagem dos estudantes ocorreram na identificação dos alimentos que causam a obesidade. A relação dos alimentos calóricos com o desenvolvimento de diabetes persistiu após a realização das atividades investigativas. Admitimos que nas atividades aplicadas para levantar os conhecimentos prévios não há indicação de diabetes, mas os estudantes citam essa doença ao resolverem uma das atividades investigativas. Assim, consideramos que os alunos já tinham conhecimento dessa doença e a relacionavam com ingestão em excesso de lipídios e açúcares. Esse fato confirma que os conhecimentos prévios têm relevância fundamental para o processo de transferência.

\section{Considerações Finais}

Estudos na atualidade têm demonstrado os problemas nutricionais dos brasileiros. Pesquisas apontam também as dificuldades referentes à compreensão conceitual e procedimental sobre alimentos e nutrientes de alunos da Educação Básica.

Os projetos e metodologias diferenciadas, que têm por objetivo o trabalho de conscientização de estudantes sobre a necessidade de uma alimentação saudável para a manutenção da saúde, podem apresentar resultados mais satisfatórios se houver clareza quanto à compreensão conceitual dos estudantes. Como afirma Pozo (1998), a aprendizagem atitudinal, que visa à conscientização dos alunos sobre determinados assuntos, depende da compreensão dos conteúdos conceituais. As atividades de ensino desenvolvidas e aplicadas ao nono ano proporcionaram aos estudantes momentos de interação entre os participantes dos grupos, discussões do problema, emissão de hipóteses, percepção de evidências e conexão aos conhecimentos científicos no momento em que buscavam informações em textos para resolução do problema e reflexão para reformulação das hipóteses ao confrontarem com o conhecimento científico. 
Concluímos que as atividades de investigação que foram aplicadas possibilitaram a um número expressivo de estudantes a transferência de significados claros e estáveis para novas situações de ensino, considerada por Ausubel (2000), como transferência positiva. Conforme aponta Salmerón (2013), a transferência de conhecimentos que os estudantes necessitam fazer para outras situações, até mesmo as que envolvem o cotidiano, é um dos aspectos fundamentais que devem ser discutidos nas situações de ensino. $\mathrm{O}$ autor ressalta a necessidade de se investir em estudos que discutam a transferência de conhecimentos e as situações de ensino que a favoreçam. Neste sentido, o estudo realizado mostrou que a utilização de atividades investigativas aplicadas aos alunos, a qual constituiu uma metodologia de ensino alternativa ao modelo tradicional, promoveu relativamente aprendizagem satisfatória dos estudantes quanto aos conhecimentos declarativos sobre alimentação. Essa metodologia contribui não apenas para a aprendizagem de conceitos dos estudantes, mas também de procedimentos referentes à resolução de problemas, emissão de hipóteses, comunicação dos resultados, aspectos que dificilmente são contemplados no ensino tradicional que visa a transmissão/recepção de conhecimentos.

Neste estudo, apesar de terem sido utilizados rótulos e tabelas nutricionais, não tivemos por objetivo a análise dos conhecimentos procedimentais quanto à leitura desses materiais. Admitimos serem necessários novos estudos que discutam a realização de transferências para conhecimentos do tipo procedimental que envolvem o tema alimentação.

As implicações para o ensino concernentes aos resultados apresentados indicam que os estudantes têm compreensão equivocada quanto aos conceitos que se referem aos conteúdos sobre alimentos. A falta de clareza, de estabilidade e de consolidação desses conhecimentos poderá comprometer o avanço no entendimento de outros conteúdos referentes ao tema e também na mudança de atitudes quanto à valorização do consumo de alimentos saudáveis.

O período escolar, compreendido como Educação Básica, é um momento adequado para o desenvolvimento da conscientização, valorização e mudanças de hábitos que visem escolhas de uma alimentação mais adequada. No entanto, há necessidade de que sejam oportunizados aos alunos a base conceitual, a utilização de metodologias apropriadas e desafiadoras que promovam a aprendizagem e facilitem a transferência dos conhecimentos escolares tanto para novas situações de ensino como para o cotidiano.

\section{Agradecimentos}

Agradecemos a Fundação Nacional de Desenvolvimento do Ensino Superior (FUNADESP) pelo apoio financeiro a esta pesquisa.

\section{Referências}

ALMEIDA, R. R.; COUTINHO, F. A.; CHAVES, A. C. L. Percepção de alunos do ensino médio sobre a utilização de recursos multimídia no ensino de biologia. In: ENCONTRO NACIONAL DE PESQUISA EM EDUCAÇÃO EM CIÊNCIAS, 7., 2009, FlorianópolisSC. Anais... Florianópolis: ABRAPEC, 2009. Disponível em: <http://www.foco.fae.ufmg. br/conferencia/index.php/enpec/viienpec/paper/view/621/75>. Acesso em: 15 out. 2010. 
Atividades de investigação e a transferência de significados ...

AMARAL, C. L. C.; XAVIER, E. S.; MACIEL, M. D. Abordagem das relações ciência/ tecnologia/sociedade nos conteúdos de funções orgânicas em livros didáticos de química do ensino médio. Investigações em Ensino de Ciências, Porto Alegre, v. 14, n. 1, 101-114, 2009.

AUSUBEL, D. P. Aquisição e retenção de conhecimentos: uma perspectiva cognitiva. Lisboa: Plátano, 2000.

AUSUBEL, D.; NOVAK, J.; HANESIAN, H. Psicología educativa: un punto de vista cognoscitivo. México: Trillas, 1976.

AZEVEDO, M. C. P. S. Ensino por investigação: problematizando as atividades em sala de aula. In: CARVALHO, A. (Org.). Ensino de ciências: unindo a pesquisa e a prática. São Paulo: Pioneira, 2004. p. 19-34.

BATISTA FILHO, M.; RISSIN, A. A transição nutricional no Brasil: tendências regionais e temporais. Cadernos de Saúde Pública, Rio de Janeiro, v. 1, 2003. Disponível em: <http:// www.scielo.br/scielo.php?script=sci_arttext\&pid=S0102-311X2003000700019 >. Acesso em: 15 nov. 2016.

BEN-HUR, M. Aprendizagem e transferência. Disponível em: http://www.cdcp.com.br/ artigo-aprendizagem.php. >. Acesso em: 26 ago. 2017.

BRASIL. Ministério da Educação. Pacto Nacional pelo Fortalecimento do Ensino

Médio. Brasilia, 2014. Disponível em: < http://pactoensinomedio.mec.gov.br/images/pdf/ doc_orientador_proemi_2014.pdf>. Acesso em: 15 nov. 2016.

- Ministério da Saúde. Secretaria de Vigilância em Saúde. Política Nacional de Promoção da Saúde. Portaria n ${ }^{\circ} \mathbf{6 8 7}$ MS/GM, de 30 de março de 2006. Brasília: Ministério da Saúde, 2006. 60 p. (Série B. Textos Básicos em Saúde).

. Parâmetros curriculares nacionais: saúde. Brasília, 1997.

. Ministério de Educação e do Desporto. Referencial Curricular Nacional para
educação infantil. Brasília, 1998.

. Ministério da Saúde. Saúde na escola. Brasília, 2009.

CAMPOS, M. C. C.; NIGRO, R. G. Didática de ciências: o ensino-aprendizagem como investigação. São Paulo: FTD, 1999.

CARMO, M. B. et al. Consumo de doces, refrigerantes e bebidas com adição de açúcar entre adolescentes da rede pública de ensino de Piracicaba. Revista Brasileira de Epidemiologia, São Paulo, v. 9, p. 121-30, 2006.

CARVALHO, A. M. P. Las practices experimentales en el proceso de enculturación científica. In: GATICA, M. Q, \& A. ADÚRIZ-BRAVO (Eds.). Ensenar ciencias en el Nuevo milenio: retos e propuestas. Santiago: Universidade Católica de Chile, 2006.

CARVALHO, J.C.; BOSSOLAN, N.R.S. Algumas concepções de alunos do ensino médio a respeito das proteínas. In: ENCONTRO NACIONAL DE PESQUISA EM EDUCAÇÃO EM CIÊNCIAS, 7., 2009, Florianópolis-SC. Anais... Florianópolis: ABRAPEC, 2009.

Disponível em: < http://posgrad.fae.ufmg.br/posgrad/viienpec/pdfs/992.pdf>. Acesso em: 20 out. 2010. 
DEBOER, G. E. Historical perspectives on inquiry teaching in schools. In: FLICK; LEDEMAN. Scientific inquiry and nature of science. Implications for teaching, learning, and teacher education. Springer, 2006. p. 17-36.

FERNANDES, P. S. et al. Avaliação do efeito da educação nutricional na prevalência de sobrepeso/obesidade e no consumo alimentar de escolares do ensino fundamental. Jornal de Pediatria, Rio de Janeiro, v. 85, n. 4, p. 315-321, 2009.

FREDERIKSEN, N. The Real Test Bias: Influences of Testing on Teaching and Learning. American Psychologist, v. 39, 193-202, 1984.

GIL-PÉREZ, D. et al. Para uma visão não deformada do trabalho científico. Ciência \& Educação, Bauru, v. 7, n. 2, p. 125-153, 2001.

GIL-PÉREZ, D. Contribución de la Historia y de la Filosofía de las Ciencias al desarrolo de un modelo de enseñanza: aprendizaje como investigación. Enseñanza de Las Ciencias, v.11 n. 2, p. 197- 212, 1993.

GIL-PÉREZ, D.; VALDÉS-CASTRO, P. La orientación de las prácticas de laboratorio como investigación: un ejemplo ilustrativo. Enseñanza de las Ciencias, v. 14, n. 2, p. 155-163, 1996.

LEITE, R. C. M.; FEITOSA, R. As contribuições de Paulo Freire para um ensino de ciências dialógico. In: ENCONTRO NACIONAL DE PESQUISA EM EDUCAÇÃO EM CIÊNCIAS, 8., 2011, Campinas-SP. Atas... Campinas: ABRAPEC, 2011. Disponível em: <http://www. nutes.ufrj.br/abrapec/viiienpec/resumos/R0753-1.pdf>. Acesso em: 05 mar. 2016.

LUZ, M. R.M.P.; DA POIAN, A. T. O ensino classificatório do metabolismo humano. Cienc. Cult., São Paulo, v. 57, n. 4, p. 43-45, 2005. Disponível em: < http:/ / cienciaecultura. bvs.br/scielo.php?script $=$ sci_arttext\&pid=S0009-67252005000400023\&lng=en\&nrm=iso $>$. Acesso em: 03 nov. 2016.

MALDANER, O. A.; ZANON, L. B. Situação de estudo: uma organização do ensino que extrapola a formação disciplinar em ciências. In: MORAES, R.; MANCUSO, R. (Org.). Educação em ciências: produção de currículos e formação de professores. Ijuí: Ed. Unijuí, 2004. p. 43-64.

MARANDINO, M. A prática de ensino nas licenciaturas e a pesquisa em ensino de ciências: questões atuais. Caderno Brasileiro de Ensino de Física, Florianópolis, v. 20, n. 2, p. 168$193,2003$.

MOREIRA, M. A. Aprendizaje significativo crítico. Indivisa: boletín de estudios e investigación, Madrid, v. 6, p. 83-102, 2005.

NATIONAL RESEARCH COUNCIL. Inquiry and the national science education standards: a guide for teaching and learning. New York: National Academy Press, 2000.

NEWMAN Jr. W. J, et al. J. Dilemmas of teaching inquiry in elementary science methods. Journal of Science teacher education, v. 15, n. 4, pp. 257-279, 2004.

OLIVEIRA, C. L.; FISBERG, M. Obesidade na infância e adolescência: uma verdadeira epidemia. Arquivos Brasileiros de Endocrinologia e Metabologia, São Paulo, v. 47, n. 2, p. 107-108, 2003. 
Atividades de investigação e a transferência de significados ...

OLIVEIRA, M. F. A; LUZ, M. R. M. P. Identificando os nutrientes energéticos: uma abordagem baseada em ensino investigativo para alunos do ensino fundamental. Revista Brasileira de Pesquisa em Educação em Ciências, Rio de Janeiro, v. 8, n. 2, 2008.

PERRENOUD, P. et al. As competências para ensinar no século XXI: a formação dos professores e o desafio da avaliação. Porto Alegre: Artmed, 2002.

PIPERAKIS, S. M. et al. Dietary habits of Greek primary school children. Journal of Science Education and Technology, v.16, n. 3, p. 271-278, 2007.

POZO, J. I. A solução de problemas: aprender a resolver, resolver para aprender. Porto Alegre: Artmed, 1998.

RODRÍGUEZ, J. J. G.; LEÓN, P. C. Cómo enseñar?: hacia una definición de las estratégias de enseñanza por investigación. Investigación en la Escuela, La Rioja, n. 25, p. 5-16, 1995.

SALMERÓN, L. Actividades que promueven la transferencia de los aprendizajes: una revisión de la literatura. Revista de Educación, Madrid, número extraordinário, p. 34-53, 2013. Disponível em: <http://www.mecd.gob.es/dctm/revistadeeducacion/doi/re2013253. pdf?documentId=0901e72b8171df83>. Acesso em: 05 jun. 2016.

SÁNCHEZ, A.; LÓPEZ FERNÁNDEZ, R. La transferencia de aprendizaje algorítmico y el origen de los errores en la sustracción. Revista de Educación, Madrid, n. 354, p. 429-445, 2011. Disponível em: <http://www.revistaeducacion.mec.es/re354/re354_17.pdf>. Acesso em: 01 jun. 2016.

SASSERON, L. H, CARVALHO, A.M.P. Alfabetização Científica: uma revisão bibliográfica. Investigações em Ensino de Ciências, v. 16, n. 1, p. 59-77, 2011.

. A construção de argumentos em aulas de ciências: o papel dos dados, evidências e variáveis no estabelecimento de justificativas. Ciência \& Educação, Bauru, v. 20, n. 2, p. 393-410, 2014.

SCHWAB, J.J., The teaching of science as enquiry. In: J.J. Schwab \& P.F. Brandwein (eds.). The teaching of science, Cambridge: Harvard University Press, p. 3-103, 1962.

SOBRAL, N. A. T.; SANTOS, S. M. C. Proposta metodológica para avaliação de formação em alimentação saudável. Revista de Nutrição, Campinas, v. 23, n. 3, p. 399-415, 2010.

Disponível em: < https://doi.org/10.1590/S1415-52732010000300008>. Acesso em: 3 jun. 2016.

SUART, R. C.; MARCONDES, M. E. R. A manifestação de habilidades cognitivas em atividades experimentais investigativas no ensino médio de química. Ciências \& Cognição, João Pessoa, v. 14, n. 1, p. 50-74, 2009.

TAMAYO, A. P.; JUÁNEZ, J. C.; MACÍAS, C. R. Conocimientos previos en Alimentación y Nutrición y su relación con el Índice de Masa Corporal de un grupo de estudiantes de un Centro Penitenciario Español: un recurso en Educación para la Salud. ENSAYOS. Revista de la Facultad de Educación de Albacete, v. 28, p. 87-100, 2014. 
TAPIA, C.; TERRERO, J.; CABRAL, J. Meta-cognición, motivación, transferencia y desarrollo, 2015. Disponível em: <https:/ /www.researchgate.net/publication/290997636_ Meta-cognicion_Motivacion_Transferencia_y_Desarrollo>. Acesso em: 1 jun. 2016.

TEIXEIRA, P. M. M. A educação científica sob a perspectiva da pedagogia histórico-critica e do movimento C.T.S. no ensino de ciências. Ciência \& Educação, v. 9, n. 2, p.177-190, 2003.

WATSON, J. R.; SWAIN, J. R. L.; Mc ROBBIE, C. Students' discussions in practical scientific inquiries. International Journal of Science Education, v. 26, n. 1, p. 25-45, 2004.

WONG, D.; PUGH, K. Learning science: a deweyan perspective. Journal of Research in Science Teaching, Hoboken, v. 38, n. 3, p. 317-336, 2001.

ZABALA, A. A prática educativa: como ensinar. Porto Alegre: Artmed, 1998.

ZABALA, M. A. Planificação e Desenvolvimento Curricular na Escola. Porto: Edições Asa, 1992.

ZOLLER, U. Science, technology, environment, society (STES) literacy for sustainability: what should it take in chem/science education? Educação Química, México, v. 24, n. 2, p. 207-214, 2013. Disponível em: <http://www.scielo.org.mx/scielo.php?script=sci_ arttext\&pid=S0187-893X2013000200005\&lng=es\&nrm=iso > . Acesso em: 19 mar. 2016.

ZOMPERO, A. F.; LABURÚ, C. E. Atividades investigativas no ensino de ciências: aspectos históricos e diferentes abordagens. Ensaio: pesquisa em educação em ciências, Belo Horizonte, v. 12, n. 3, p. 67-80, 2011.

. Significados de fotossíntese produzidos por alunos do ensino fundamental a partir de conexões estabelecidas entre atividade investigativa e multimodos de representação.

Revista Electrónica de Enseñanza de las Ciencias, Vigo, v. 13, n. 13, p. 242-266, 2014.

ZOMPERO, A. F. et al. A educação alimentar nos documentos oficiais de ensino na educação básica. Ciências \& Ideias, Nilópolis, v. 6, n. 2, p. 71-82, 2015. Disponível em: $<$ www.revistascientificas.ifrj.edu.br:8080/revista/index.php/reci/article/view/376>. Acesso em: 03 jun. 2016.

ZOMPERO, A. F.; GONÇALVES, C. E.; SAMPAIO, H. R. Estudio sobre la transferencia de significados en actividad investigativa. Revista de Educacion en Biologia, Córdoba, v. 17, n. 2, 2014. Disponível em: <www.revistaadbia.com.ar/ojs/index.php/adbia/article/ viewFile/326/187>. Acesso em: 25 set. 2016.

Artigo recebido em 01/07/2016. Aceito em 07/12/2016.

Endereço para contato: Universidade Norte do Paraná, Centro de pesquisa, Jardim Piza, Rua Marselha 591, CEP 86015-320, Londrina, PR, Brasil. 